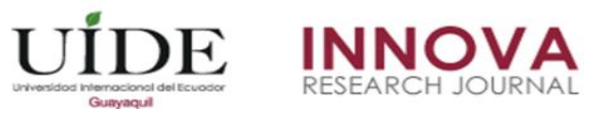

INNOVA Research Journal, ISSN 2477-9024

(Agosto, 2018). Vol. 3, No.8.1 pp. 99-112

DOI: https://doi.org/10.33890/innova.v3.n8.1.2018.770

URL: http://revistas.uide.edu.ec/index.php/innova/index

Correo: innova@uide.edu.ec

\title{
La caducidad tributaria en el impuesto a la renta: aplicación práctica en la legislación ecuatoriana
}

\section{Tax expiration in income tax: practical application in ecuadorian legislation}

Samuel Morales Castro

Universidad Politécnica Salesiana, Ecuador

Universidad de Guayaquil, Ecuador

Eco. Francisco Xavier León Sánchez. Magister

Universidad Politécnica Salesiana, Ecuador

Autor para correspondencia: moralescastrosamuel@gmail.com, ficasesores@gmail.com Fecha de recepción: 20 de julio de 2018 - Fecha de aceptación: 30 de agosto de 2018

Resumen: El sistema tributario ecuatoriano ha procurado garantizar su excelencia normativa promulgando, reformando y mejorando la legislación de la materia a fines de optimizar la imposición fiscal; de tal suerte que, el presente trabajo con asiento en la legislación constitucional, investiga, a través de un caso práctico, la eficiencia de la relación jurídica tributaria, al enfrentarse en polos diametralmente opuestos, el Servicio de Rentas Internas, como titular de la relación jurídica y la empresa como persona jurídica y sujeto obligado a efectuar los correspondiente pagos del impuesto a la renta. En ese cauce, el trabajo se centra en la caducidad tributaria, como institución de Derecho que prescribe el paso del tiempo ante la inacción del titular, hasta su total decadencia y pérdida, conllevando en consecuencia a la imposibilidad de cobro o lo que es igual a la exoneración del pago del contribuyente, en virtud del principio de seguridad jurídica. Esos derroteros, generan a un análisis sopesado de la caducidad, tanto en la legislación como en la jurisprudencia ecuatoriana, al aplicarse a la dinámica empresarial en el tráfico jurídico cotidiano. Palabras claves: impuesto a la renta; prescripción; caducidad; seguridad jurídica; contribuyente

Abstract: The Ecuadorian tax system has tried to guarantee its normative excellence by promulgating, reforming and improving the legislation of the matter in order to optimize taxation; in such a way that, the present work with seat in the constitutional legislation, investigates, through a practical case, the efficiency of the tributary legal relation, when confronting in diametrically opposed poles, the Internal Revenue Service, as owner of the relation legal entity and the company as a legal entity and subject obliged to make the corresponding payments of income tax. In this channel, the work focuses on the tax expiration, as an institution of law that prescribes the passage of time before the inaction of the owner, until its total decline and loss, leading consequently to the impossibility of collection or what is equal to the exemption of the taxpayer's payment, by virtue of the principle of legal security. These courses generate an analysis based on expiration, both in legislation and in Ecuadorian jurisprudence, when applied to business dynamics in everyday legal transactions.

Key Words: income tax; prescription; expiration; legal security; taxpayer 


\section{Introducción}

Una antigua disquisición que ha generado no poco malentendidos en la doctrina y la práctica, son las relativas a la aplicación del Derecho por el paso del tiempo, es decir, hacer valer derechos y ejercitar acciones conforme a los designios de la Ley; diferentes autores como mayor o menor claridad y acierto se han referido al tema, sin que exista un criterio unánime en torno a la aplicación de la prescripción y la caducidad, en materia tributaria, pues las exigencias pivotan, en dependencia de las exigencias impuestas por el Derecho Público en cada ordenamiento jurídico.

De ahí que, sentado lo anterior, el objetivo del presente trabajo esté encaminado a valorar la institución jurídica de la caducidad tributaria en el ordenamiento jurídico ecuatoriano, a la luz de su aplicación práctica, tanto por la administración tributaria, como en sede judicial; motivando que se encauce una investigación correlacional sobre el tema, en tanto se medirá la institución referida del paso del tiempo, con su correcta aplicación en la práctica cotidiana en Ecuador. Para conseguir esto se ha utilizado el método histórico, el inductivo-deductivo y también el dialéctico, de manera tal que, permita contrastar la evolución que ha tenido la caducidad desde la vigencia del Código Tributario ecuatoriano de 1975 hasta la actualidad, realizando las inferencias necesarias, para contrastar su aplicación en situaciones prácticas que atraviesan la vía administrativa, la judicial y la recursiva.

\section{La caducidad y la prescripción; diferencias prácticas sustanciales.}

El Derecho al aprehender la conducta humana y recoger en la norma los tipos más generales de ella, se convierte además de norma y valores, en un instrumento de oportunidad, donde la fragua de las relaciones jurídicas, y el cumplimiento de los derechos y obligaciones que de su concreción se derivan están inexorablemente sujetas al paso del tiempo, elemento que en el asunto bajo examen ha constituido un punto controvertido y más que ello, en el nudo gordiano de todo el debate, pues se centran las contradicciones en la liquidación de pago por diferencias en la declaración que se le efectúa a la compañía RTT S.A, sobre el impuesto a la renta correspondiente al ejercicio fiscal del año 2012, y que como refiere el funcionario actuante en el punto 19.11 de la contestación a reclamo administrativo venció de acuerdo con el noveno dígito del contribuyente (4) en fecha 16 de abril de 2013 y asevera que la facultad determinadora no se encontraba caducada, pues fue notificada dentro del plazo de 6 años establecido en el artículo 94.2 del Código Tributario. (CODIGO TRIBUTARIO, 2005)

Es procedente aclarar que la caducidad es una forma de extinción de las acciones y los derechos por el transcurso del tiempo, se aplica por ministerio de la ley y puede ser acogida de oficio por el juez. Diez Picazo y Gullón Ballesteros, para diferenciarla de la prescripción han enfatizado que "una distinción aceptable es el derivado de la naturaleza del derecho objeto de la presunta caducidad, pues esta recae sobre lo que en su momento hemos llamado derechos potestativos o facultades de configuración o modificación de una situación jurídica. Pendiente su ejercicio, la situación jurídica afectada se encuentra en una fase provisional o transitoria, que exige un rápido tránsito a la situación definitiva". ${ }^{1}$ Los propios autores enfatizan que se distingue 
del régimen jurídico de la prescripción porque no es susceptible de interrupción y porque puede ser apreciada de oficio por el juez. (DIEZ PICAZO, 2014)

Amerita la cuestión que se trae a debate, que se deje sentado desde el inicio del análisis que se diferencien ambas instituciones pertenecientes al Derecho Civil: Por su origen la caducidad puede ser convencional o legal; mientras la prescripción siempre es legal; como se refirió previamente la caducidad afecta a derechos potestativos y la prescripción a derechos subjetivos; la caducidad produce extinción del derecho automáticamente y de modo directo; la prescripción extingue el derecho solo a través de una excepción; la caducidad se aprecia de oficio por el juez; la prescripción es alegada por el demandado, la caducidad, generalmente no es susceptible de interrupción, la prescripción sí; la caducidad tiene una finalidad de concreción, en cuanto tiene a determinar previamente el tiempo en que puede ejercitarse un derecho, la prescripción teniendo en cuenta el no ejercicio de los derechos y acciones y el abandono por su titular o quien deba ejercitarlos, desemboca en la extinción de aquellos; MESINEO ha advertido que en la caducidad no llega a verificarse la adquisición del derecho por el titular; mientras que la prescripción se refiere a un derecho ya adquirido, pero su falta de ejercicio determina su extinción, la caducidad encuentra su fundamento exclusivo en ofrecer seguridad al tráfico jurídico, operando por el mero transcurso del tiempo, la prescripción se apoya en la necesidad de resolver la incertidumbre de los derechos y en una presunción de abandono por su titular; la caducidad puede apreciarse a instancia de parte o por el Tribunal, la prescripción solo se estima a instancia de parte. (GARCÉS MOREANO, 1978)

Los elementos antes citados permiten distinguir una institución jurídica de la otra, pues aunque ambas tienen base en el Derecho Común deben delimitarse a los efectos de su justa comprensión, en el asunto en comento. Estos derroteros no han sido asumidos a pede literae por el Derecho Público, del cual forma parte inexorable el Derecho Tributario, sobran argumentos para entender que "lo que puede caracterizar la caducidad es la negligencia de la Administración cuando no proceda a liquidar los tributos en los plazos que la ley señala". Es obvio que el fisco tiene conocimiento de hechos que pueden generar el pago de tributos, por lo cual está en la obligación de exigir las declaraciones y controlar ciertas actuaciones y de no hacerlo, transcurrido el tiempo previsto en la ley, caducará el derecho de liquidar el impuesto. (MOREANO, 1980) Motivos por los que debe acotarse que los actos que por ley tiene atribuida la administración, quedan enmarcados en su mayoría dentro de la potestad reglada y en ese mérito no solo han de ser congruentes con el ordenamiento jurídico, sino revestidos de legalidad y legitimidad.

De tal suerte que, García ha introducido otros distingos adicionales ,procede la prescripción de la ley que tiende a liquidar situaciones específicas en un tiempo determinado; la caducidad no solo fragua de la ley sino también de la convención de los particulares, no fundándose en aquella necesidad de orden social, sino en la peculiar índole del derecho sujeto al término prefijado, el cual es inconcebible más allá de ese propio término; destaca además que, la caducidad extingue el Derecho, mientras la prescripción extingue la acción para exigirlo y además afecta a toda clase de derechos, para que no funciones deberá existir una norma excepcional que exima de ella, o una u otra acción determinada. (GARCIA, 1996) 
Sentado los presupuestos anteriores es necesaria la precisión de las particularidades sui géneris que definen a la institución de la caducidad en materia tributaria, dos autores utilizan lupas diferentes para arribar a una misma esencia: MOGROVEJO JARAMILLO quien insiste en que "se verifica en la pérdida o el agotamiento de facultades o derechos no ejercidos en un tiempo establecido, que trasladada al Derecho Público, y en particular al tributario, implica la inhabilitación para el ejercicio de la facultad determinadora de la obligación tributaria a cargo de la administración, la consecuencia de la inacción de la administración tributaria en un tiempo establecido y no susceptible de prórroga, identificada con el ejercicio de facultades en la esfera de gestión". En ese cauce, es admitido doctrinal y legalmente que recae sobre la administración y no sobre los administrados, aconteciendo que al generarse la caducidad imposibilita a aquella la determinación de la obligación tributaria y por ende, la consecuente facultad de recaudación, que descansa en el derecho de cobro. (JARAMILLO, 2009)

FERREIRO LAPATZA "sostiene que la inercia del titular, mejor aún, el silencio de la relación jurídica durante un plazo de tiempo determinado por la Ley, significa la extinción de la deuda y, por tanto, la del correspondiente derecho de crédito de la administración. (LAPATZA, 1994)

Estos criterios incardinan hacia otro autor que con prístina intención enarbola complementadora teorías: JARACH, al acusar que "es evidente que la acción para exigir el pago de impuestos se refiere al ejercicio del derecho creditorio y su prescripción implica la extinción de una deuda; por el contrario, la acción para determinar la existencia de una obligación tributaria, no se refiere al derecho creditorio y a la deuda del contribuyente o responsable, sino al ejercicio por parte de la administración pública de sus poderes y facultades tendientes a la determinación de las obligaciones" (...) la naturaleza y eficacia meramente declarativa de la determinación no altera el distingo de las dos categorías enunciadas, ya que "los deberes y facultades del fisco están limitados en el tiempo y termina cuando el período establecido por la ley se halla cumplido, sin que ello tenga influencia alguna sobre la extinción de la obligación tributaria sustantiva". (JARACH, 1969)

En semejante cauce encontramos la opinión de Queralt, quien advierte la caducidad del procedimiento como forma de terminación del tributo, por inactividad o paralización administrativa, basado en el deber de resolver los procedimientos y en el principio de seguridad jurídica. (QUERALT, 2008)

Lo determinante en estos criterios teóricos es que aparecen sustentados en el ordenamiento tributario ecuatoriano y por eso se retoman como hilo conductor y soporte de las consideraciones que este perito realizará a posteriori, al poder aseverar: que el Código Tributario recoge tanto la caducidad que restringe el ejercicio de la facultad determinadora a cargo de la administración, al remitirse a una inactividad con respecto a un comportamiento específico, erigiéndose en un término rígido, aunque admite interrupción, extingue la facultad y opera de oficio; en tanto, la prescripción extingue el derecho al cobro del crédito tributario a favor de la administración, al vincularse solo con aquel; refiriéndose a una actividad genérica, admite suspensión o interrupción, y se dota de efecto preclusivo, al agotar el procedimiento, operando solo a petición de parte. (JARAMILLO, 2009) 
Esta línea de pensamiento doctrinal aparece reconocida por el legislador ecuatoriano en el Código Tributario, artículo 55, para el caso de la prescripción y artículo 94 para el caso de la caducidad, que se erige como centro de los alegatos de defensa de la compañía ZAPEG S.A, en la comunicación de diferencias No. DZB-GSOOCDE16-00000219-M, que trae causa de la declaración No.09201706500339340 (impuesto a la renta del ejercicio fiscal 2012) (CODIGO TRIBUTARIO, 2005); sin embargo, antes de entrar en el estudio del caso en cuestión ha de advertirse que en la comunicación de diferencias que genera la litis entre las partes incursas, existen cierto elementos que afectan la motivación del acto administrativo, pues se citan todos los preceptos legales que a pertinencia de la administración justificación su actuar en el orden procesal y material, pero se incurre en determinadas inconsistencias que dan al traste con la postura que sostienen:

Si se hace la especial remisión a lo enarbolado en relación con los artículos 24 y 25 del Reglamento para la Aplicación de la Ley del Régimen Tributario Interno, en primer término porque ninguna de las sociedades anónimas señaladas en el cuadro No.1 por el Servicio de Rentas Internas, puede clasificarse como inexistente, pues el propio legislador ha definido: "aquellas respecto de las cuáles no se puede verificar su constitución, sean a través de documentos tanto públicos o privados, según corresponda". Resultando que cada una de las enumeradas aparece relacionada en la base de datos de la Superintendencia de Compañías, Valores y Seguros, aunque en estado pasivo, pero debidamente actualizadas, luego entonces, no puede endilgársele esta categoría, como puede comprobarse en el documento que se anexa, marcado con el número 1. (Reglamento a la ley del Régimen Tributario Interno, 2004)

Semejante suerte corre la denominación de fantasmas, en los entes negociables ya enunciados previamente, pues tampoco pueden reconocérseles así, por lo narrado, y porque no existe evidencia documental alguna que demuestre que las empresas en cuestión fueran creadas bajo el efecto de la simulación.

Incluso cabe argüir en este caso que no existiendo otra legislación de índole tributaria que precise particulares al respecto, tal y como regula el artículo 2 del Código Tributario, al conceptualizar la supremacía de la ley tributaria; es obvio que de acuerdo con lo preceptuado en el artículo 14, son de aplicación las normas del Código Civil, que es derecho común a las demás ramas del ordenamiento jurídico y por su especialidad, donde aparece regulada la institución jurídica de la simulación, artículos 1723 y 1724. (CODIGO TRIBUTARIO, 2005) (CODIGO CIVIL, 2005)

Art. 1723.- El instrumento público o privado hace fe entre las partes aún en lo meramente enunciativo, con tal que tenga relación directa con lo dispositivo del acto o contrato.

Art. 1724.- Las escrituras privadas hechas por los contratantes, para alterar lo pactado en escritura pública, no surtirán efecto contra terceros. Tampoco lo surtirán las contraescrituras públicas, cuando no se ha tomado razón de su contenido al margen de la escritura matriz cuyas disposiciones se alteran en la contraescritura, y del traslado en cuya virtud ha obrado el tercero. 
De lo que sigue, el incordio que se genera cuando puede apreciarse en la documentación anexa, que las referidas sociedades anónimas con las que RTT S.A realizó negocios de venta, en el año 2012, estaban activas, aumentaron el capital, poseían sus escrituras de constitución y todos los documentos contables en regla, siendo intrascendentes a los efectos probatorios del principal de esta pericia, el estado en que se encuentren en la actualidad, pues la administración tributaria ha fiscalizado y emitido la comunicación de diferencias sobre la base del impuesto a la renta declarado por el cliente en el año 2012.

El tema de la simulación, que es de los que concita más intrincada complejidad en la doctrina, aunque escueto en el Código Civil ecuatoriano, si ha estado presente en la jurisprudencia ${ }^{2}$; a esos fines es necesario precisar que doctrinalmente, reconocidos autores se han pronunciado al respecto:

AlBALADEJO, quien refiere, "es simulado el negocio, que sin quererlo de verdad, se finge celebrar, llevando a cabo la conducta exterior en que consiste el otorgamiento del negocio verdadero que sea, pero sin voluntad de realizar efectivamente el tal negocio, que solo aparenta, pues el otorgante $u$ otorgantes no tienen deseos de darle vida, sino que solo persiguen (con el fin que sea) hacer creer a los demás que es realidad lo que únicamente es una engañosa apariencia vacía del necesario propósito negociar, propósito que no se tiene, sino que solo se finge". (ALBALADEJO, 2005)

Semejante prestancia pero en cuerda más integradora muestran ALESSANDRI, SOMARRIVA y VODANOVIC, cuando advierten que "la simulación es la declaración de un contenido de voluntad no real, emitido conscientemente y de acuerdo entre las partes o entre el declarante y la persona a la cual va dirigida la declaración para producir con fines de engaño la apariencia de un acto jurídico que no existe o es distinto de aquel que realmente se ha llevado a cabo.

(ALESSANDRI, 2005)

Ambas definiciones encierran los verdaderos elementos de la simulación como institución de Derecho Civil que pervive en el ámbito negocial, pues no puede obviarse, que desacierta el Servicio de rentas Internas cuando sostiene esta tesis, porque en Ecuador la constitución de una

\footnotetext{
${ }^{2}$ A propósito de la simulación pueden consultarse las sentencias 0154-2008 dictada en el expediente , juicio 02372006, a ese respecto al resolver el recurso de casación interpuesto la Corte Nacional de Justicia advierte: "La acción de simulación de contrato tiene como objeto hacer reconocer la inexistencia de una relación jurídica o la existencia de otra distinta a la que manifestaron en el contrato simulado y que se haga prevalecer la voluntad real de las partes; $o$, que se declare la nulidad absoluta cuando la simulación es ilícita.

con igual rasero, pero abundando en cuestiones técnicas respecto a esta institución jurídica se pronuncia en la sentencia 0078-2017, dictada en el juicio 0363-2016:" los elementos esenciales de la simulación son: i) disconformidad entre lo declarado y lo querido; ii) acuerdo para producir disconformidad; iii) fin de engañar a terceros “(...) en principio, lo simulado es lo opuesto a lo verdadero y real...un acto jurídico simulado, es el que tiene apariencia contraria a la realidad, o porque no existe en lo absoluto, o porque es distinto de como aparece... son elementos esenciales de la simulación: i. disconformidad consciente entre lo declarado y lo querido realmente; ii. acuerdo de las partes en producir esta disconformidad en relación a la voluntad interna y la declarada; y, iii. con el fin de engañar a terceros, engaño que se realiza creando un contrato aparente que no existe o existe de distinta manera (...)"“(...) la simulación se expresa de forma absoluta y de forma relativa; caracteriza a la primera porque los contratantes aparentan celebrar un negocio que no han querido en ninguna de sus partes...caracteriza a la simulación relativa el hecho de que los contratantes ciertamente han querido un determinado negocio pero ocultan su naturaleza, alteran su contenido o condiciones. esta forma de simulación se hace práctica respecto de la naturaleza del negocio, de interposición ficticia de personas y del contenido o condiciones del negocio jurídico (...)"
} 
compañía tiene carácter contractual, de acuerdo con lo preceptuado en el artículo 1 de la ley de Compañías que preceptúa:

“Art. 1.- Contrato de compañía es aquél por el cual dos o más personas unen sus capitales o industrias, para emprender en operaciones mercantiles y participar de sus utilidades. Este contrato se rige por las disposiciones de esta Ley, por las del Código de Comercio, por los convenios de las partes y por las disposiciones del Código Civil”. (LEY DE COMPAÑIAS, 1999)

Súmese a esta naturaleza contractual, el uso indistinto en la doctrina, la ley y la jurisprudencia ecuatoriana de los términos compañía y sociedad, de tal suerte que, no puede obviarse la regulación del artículo 1757 del Código Civil, que define el contrato de sociedad, con independencia que una parte de la doctrina espete que se tratan, la sociedad y la compañía, de conceptos de una dispar entidad.

“Art. 1957.- Sociedad o compañía es un contrato en que dos o más personas estipulan poner algo en común, con el fin de dividir entre sí los beneficios que de ello provengan. La sociedad forma una persona jurídica, distinta de los socios individualmente considerados”. (CODIGO CIVIL, 2005)

Concluyendo en este punto que, aunque se denominen las acusadas compañías o sociedades enunciadas por el SRI en su cuadro No.1 de la comunicación de diferencias, como fantasmas, inexistentes o simuladas, términos que tienen diferentes matices y por ende, efectos jurídicos, caen por su peso esos argumentos, que no encuadran en la preceptiva legal del sistema normativo ecuatoriano y lo que resulta más contradictorio, en el año 2012 estaban en pleno ejercicio económico, de acuerdo con su misión social, lo cual desdice los argumentos superfluos que se alegan y por otro lado, en Ecuador la creación de una compañía opera y adquiere plenos efectos jurídicos, al momento en que se inscribe en el Registro Mercantil correspondiente a su génesis, trámite que tiene efectos constitutivos, pues ese asiento registral genera una situación jurídica de contenido nuevo, cual es: que esas compañías multimencionadas han adquirido personalidad jurídica, que para el Derecho Societario, tutelado por la preceptiva civil, es ser sujeto de derechos y obligaciones, en esencia, participar activamente en la vida en relación, en los negocios y en tanto estas que analizamos tienen la denominación de S.A, están sujetas al control y vigilancias de la Superintendencia de Compañías Valores y Seguros, conforme demandan las cuartetas legales fijadas en los artículos 18 y 20 de la mentada ley societaria ecuatoriana. La que realizó todos sus controles para el año 2012 y antes de esa data, sin que emergiera irregularidad alguna. (LEY DE COMPAÑIAS, 1999)

Adpero, dando por sentado lo anterior y las presunciones que está facultada para realizar la administración, la buena fe es la conciencia de haberse adquirido el dominio de la cosa por medios legítimos, exentos de fraude y de cualquier otro vicio, presumiéndose, salvo en los casos que la ley determine lo contrario; la mala fe hay que probarla, según los artículos 721 y 722, del Código Civil ecuatoriano, motivos de suficiente peso para desvirtuar los argumentos que en el año 2012, las empresas relacionadas en el cuadro No.1 ya mentado por la administración actuante, tuvieran el carácter de inexistentes o fantasmas, pues el estado que las mismas presenten en la Superintendencia de Compañías en la actualidad no trasciende al debate, pues los 
términos de este, los ha fijado el ente administrativo y circunscritos al año 2012, y específicamente al impuesto a la renta de la compañía RTT S.A, no le es dable utilizar otros argumentos fácticos y legales que no se ajustan a la realidad de la mencionada y agraviada entidad empresarial. (CODIGO TRIBUTARIO, 2005)

El elemento central en que se apoya este dictamen pericial solicitado por la compañía RTT S.A, descansa en la procedencia o no de la caducidad en la determinación tributaria, emitida por el Director Zonal No.8 del Servicio de Rentas Internas, al amparo del artículo 94 del Código Tributario y la procedencia de aplicar, los numerales 1 o 2, en dependencia de las circunstancias sobre las que se subsume el material factual del caso en cuestión, a cuyo tenor se efectúan las siguientes consideraciones:

Los artículos 94 y 95, del Código tributario ecuatoriano posee sus antecedentes más remotos en el artículo 54 de la ley del Impuesto a la renta de 1941: el impuesto se modifica al constituirse netamente por fuente de ingresos y se acerca al concepto de renta integral; el literal c) del mentado cuerpo de normas, establecía: en relación con la circunstancia de ser posible revisar las declaraciones presentadas o que debieron haber presentado anualmente los contribuyentes. La disposición normativa bajo examen permitía realizar tales intervenciones en cinco años, para cualquiera de los eventos, con declaración previa o sin ella. (GARCÉS MOREANO, 1978) ${ }^{3}$

Después de sucesivas modificaciones a la ley mencionada Ley, la regulación de la caducidad contenida en el artículo 94 se ha mantenido incólume y en tal sentido, dada la finalidad de este dictamen, es obligatorio razonar sobre el tema:

Artículo 94.- Caducidad.- Caduca la facultad de la administración para determinar la obligación tributaria, sin que se requiera pronunciamiento previo:

En tres años, contados desde la fecha de la declaración, en los tributos que la ley exija. Dentro de las particularidades de este caso, que es el más controvertido en el Derecho tributario ecuatoriano, se debe señalar que opera exclusivamente cuando los contribuyentes han presentado su declaración impositiva, con arreglo a las formalidades legales establecidas.

Que la declaración constituya el reflejo fiel de su realidad económica.

Que se haya formulado dentro de los plazos pertinentes fijados por la ley.

Cumpliendo esos requisitos, servirán de base para que el sujeto activo efectúe la determinación: aquellas declaraciones que los contribuyentes las hubieran formulado conteniendo todos los hechos imponibles susceptibles de grabación y las demás circunstancias

\footnotetext{
${ }^{3}$ El propio autor sigue el tracto sucesivo de esta legislación destacando que en 1959 se sancionó la ley que creó el Tribunal Fiscal de la República expedida en 1959, en cuyo artículo 33, se regula la situación referente al tiempo para ejercitar la acción de lo indebidamente pagado, fijada en cinco años, al igual que el tiempo de la prescripción de las acciones del fisco para recaudar los tributos. Después en 1962, se efectuaron modificaciones al sistema vigente, específicamente el artículo 112 hace referencia a la caducidad de la facultad administrativa, distinguiéndola de la prescripción y señalando los plazos que han de corresponder a cada una, cinco y siete años para las acciones referidas a la refiscalización, fiscalización de personas que han declarado y las que no lo han hecho respectivamente. En esta línea continuaron el Código Fiscal de 1963 y la Ley del Impuesto a la Renta de 1964, las que innovaron, según el citado tributarista, al reducir a tres años, el plazo que el contribuyente tiene para repetir lo indebidamente pagado.
} 
que en la medida de la obligación incidan, siendo susceptibles de glosas o cargos, dentro de los tres años contados desde la fecha en que debió presentarse la declaración. (GARCÉS MOREANO, 1978)

En seis años, contados desde la fecha en que venció el plazo para presentar la declaración, respecto de los mismos tributos, cuando no se hubieren declarado en todo o en parte; $y$,

Este apartado se ha formulado por el legislador para aquellos sujetos pasivos, contribuyentes o no, que obligados legalmente, no formulen las oportunas declaraciones de impuestos por ningún concepto y dentro de los plazos previstos en la ley. Regulación de la que se colige la presencia de dos situaciones diversas:

Absoluta falta de declaración. Esta textualmente se relaciona con una omisión ineludible, que genera vulneración legal.

Que los sujetos pasivos que hubieran presentado sus declaraciones impositivas dentro de los plazos previstos por la ley, hubieran omitido uno o más hechos generadores, que influyan, en última instancia en la medida de la obligación tributaria. (CODIGO TRIBUTARIO, 2005)

Sobre estos dos puntos se centra el debate en el caso que nos ocupa, pues la Compañía RTT S.A, presentó en el plazo reglamentado la declaración del impuesto a la renta correspondiente al año 2012, y en ese sentido le fue notificada la Liquidación por pago de diferencias No.09201706500339340, emitida por el Director Zonal 8 del Servicio de Rentas Internas, de fecha 13 de abril de 2017, notificada en fecha 26 de abril del año 2017.

Del acto administrativo cuestionado se puede advertir que la administración está subsumiendo su actuar, en el apartado 2 del artículo 94 del Código Tributario, que le permite extender su función verificadora y sancionadora hasta los 6 años; mientras la Compañía de mención objeta las referidas imputaciones con descanso en el apartado primero del artículo 94, por lo que a ese tenor, es menester pronunciarnos, de acuerdo con nuestro saber y razonamiento. (CODIGO TRIBUTARIO, 2005)

Ameritan las circunstancias en cuestión que se retomen algunas precisiones efectuadas por la Corte Nacional de Justicia respecto a la aclaración de los términos legales de ambas cuartetas legales, de tal suerte que RTT S.A presentó su declaración para el ejercicio económico del año 2012, respecto al impuesto a la renta en tiempo y forma y la administración le viene inculpando de que dicho acto, se encuentra incompleto; motivos por los que debemos tomar como fundamento la triple reiteración que existe respecto a cuándo pueden considerarse incompletas las actas de declaración, a esos efectos, se remite el perito actuante a las sentencia 227-2004, Registro Oficial No.45 de 19 de marzo de 2007:

“QUINTO: (...) Esta Sala, en fallo de triple reiteración que constituye precedente jurisprudencial obligatorio en los términos del artículo 19 de la Ley de Casación, ha reconocido que una declaración es incompleta cuando existe ocultación de un rubro y no 
por omisiones o inexactitudes de rubros (Recursos 64-2001, R.O 265, martes 3 de febrero de 2004; 69-2002, R.O 117, Jueves 3 de julio del 2002; 164-2003, R.O 556, viernes 1 de abril del 2005 pues sostener lo contrario llevaría a la absoluta afirmación de que toda prescripción es de siete años"

En igual medida la propia Sala pero ya refiriéndose directamente a la caducidad de la facultad determinadora de la administración ha precisado en el Recurso 336-2012, de fecha 21 de junio de 2013: "6.3 El punto de discusión radica en definir el alcance de la frase del artículo 94.2 del COT "Cuando no se hubieran declarado en todo o en parte", que es la determinante para establecer que la caducidad opera o no en seis años. Sobre el tema esta sala ha establecido que el sentido y alcance de la frase es que ello ocurre cuando se ha ocultado deliberadamente algún tipo de ingresos o grupo de renta, más no cuando existen diferencias en su declaración o contabilidad"

Lo cual aparece reiterado y explicado con detenimiento en el Recurso 104-2007: "Esta sala de forma reiterada ha hecho esta diferenciación en distintos fallos. En general, ha señalado que una declaración se encuentra incompleta únicamente cuando existe ocultación de un rubro, y no cuando se evidencian omisiones o inexactitudes de rubros, pues lo contrario supondría que toda caducidad es de seis años, y que la administración para no ver extinguida su facultad determinadora por obra de la institución jurídica de la caducidad, podría en todo caso alegar que existe falta parcial de declaración, lo cual sin lugar a dudas no es el espíritu que el legislador confirió a esta norma cuando previó los dos diferentes supuestos"

Traídos a colación los fallos anteriores y tratándose del impuesto a la renta correspondiente al ejercicio fiscal del año 2012 por la compañía de marras, conviene a los fines de este asunto se precise que considera la ley renta:

En la Ley del Régimen Tributario Interno, en su art. 2, establece que renta es:

Art. 2.- Concepto de renta. - Para efectos de este impuesto se considera renta:

1.- Los ingresos de fuente ecuatoriana obtenidos a título gratuito o a título oneroso provenientes del trabajo, del capital o de ambas fuentes, consistentes en dinero, especies o servicios; y

2.- Los ingresos obtenidos en el exterior por personas naturales domiciliadas en el país o por sociedades nacionales, de conformidad con lo dispuesto en el artículo 98 de esta Ley. (Ley del Régimen Tributario Interno, 2010)

Comparado lo anterior con el acta de liquidación por pagos de diferencias, baste advertir que no puede hablarse en el caso de ZAPEC que su acta de declaración de impuesto a la renta del año 2012 tenga el carácter de incompleta, en tanto las observaciones que viene efectuando la administración tributaria actuante, tienen un carácter contable o de diferencias que a su juicio existen en la contabilidad y nunca de ocultación de rentas por parte del ente empresarial cuestionado, habida cuenta que se reitera en todo el análisis que realiza la administración en cuestión en el acto tantas veces invocado, que descansa en diferencias que encuentra en la declaración de RTT S.A, las que provienen de transacciones con entidades que pueden o no 
presentar irregularidades, tal y como se narra, pero que descansan sobre temas de esa índole y no sobre la ocultación de rentas, como pretende demostrar el sujeto activo de esta relación jurídica.

A ese tenor el propio, a continuación del cuadro No,1 del acta de liquidación de pago por diferencias, se relacionan una serie de puntos, saltan a la vista los números 4, 5, 6, 7, 9, por citar algunos, son elementos relativos a estricta contabilidad o que tiene directamente que ver con la declaración del impuesto a la renta del año 2012 de la compañía y no con el ocultamiento de rentas, y en tal sentido no puede el Servicio de Rentas Internas acomodar el término de caducidad a su antojo, con asiento en el numeral segundo del artículo 94, pues implicaría vulnerar los principios de legalidad y seguridad jurídica, ambos con rango constitucional en la materia que nos ocupa, según la letra del artículo 300 del magno texto:

"Art. 300.- El régimen tributario se regirá por los principios de generalidad, progresividad, eficiencia, simplicidad administrativa, irretroactividad, equidad, transparencia y suficiencia recaudatoria. Se priorizarán los impuestos directos y progresivos.

La política tributaria promoverá la redistribución y estimulará el empleo, la producción de bienes y servicios, y conductas ecológicas, sociales y económicas responsables”. (Constitución de la República de Ecuador, 2008)

Significando este particular, ceñirse en el actuar administrativo al ordenamiento jurídico, es decir, a las normas, como la antes citada, que sientan pautan y limitan tanto el ejercicio de los órganos del estado en su actuar individual y en el vinculante, cuando establecen relaciones jurídicas con las personas naturales y jurídicas, que producen efectos jurídicos, como en el caso en comento. Muestra de lo anterior y con efectos contraproducentes para la administración, es la cita que se refiere al Recurso de Casación No.12-2008, de fecha 18 de febrero de 2009, publicado en la edición especial del Registro Oficial No.89, de 23 de noviembre de 2010, donde la administración cita textualmente en el apartado 19.5, donde cita el apartado tercero de la sentencia:

"La Sala observa que la sentencia no valora todos los elementos y circunstancias en torno a si los ingresos detectados por la Administración y no declarados por el contribuyente constituyen o no ocultamiento de ingresos, omisión del juzgador que deviene en falta de aplicación de los principios aplicables a la valoración de la prueba, de manera especial del convenido en el artículo 13 y particularmente en el artículo 17 del Código Tributario. Para esta Sala la apreciación de los elementos y circunstancias que rodean la no inclusión de determinados ingresos en la declaración del contribuyente, no necesariamente puede significar ocultamiento pues podría provenir de errores, omisiones, olvidos de buena fe que no evidencien un ánimo deliberado de disminuir los ingresos y por ende la base imponible y el tributo. Elementos como la cuantía, el origen, la oportunidad de la percepción, pueden ser indicios de la existencia del ánimo deliberado de perjudicar al fisco y por ende no pueden ser considerados como ocultamiento. Por el contrario cuando la cuantía del ingreso no declarado es significativa con relación al total del mismo o no pueda justificarse razonablemente el motivo de la omisión, el juzgador podría concluir que se trata de ocultamiento que en todo caso ha de ser deliberado para que se siga como consecuencia que la caducidad de la facultad 
verificadora se extienda en la magnitud señalada en el inciso segundo del artículo 94 del Código Tributario".

Sin embargo omite, el párrafo último del referido análisis que formulado como sigue, brinda una realidad bien diferente: "En el proceso consta que el contribuyente declaró ingresos por \$335.363.25 mientas las fuentes consultadas por la administración establecen que los ingresos ascendieron a \$ 614.740.41 arrojando una diferencia de \$279.377.16 en el ejercicio económico del año 2000. Esta diferencia es evidentemente significativa y el contribuyente, ni en el reclamo administrativo ni en la demanda en contra de la Resolución negativa de dicho reclamo se ha pronunciado taxativamente impugnando la existencia de tales ingresos no declarados".

Lo cual no acontece en el asunto que traemos al análisis en esta oportunidad, pues se enumeran en la contestación al reclamo administrativo una serie de deficiencias relativas a la contabilidad de RTT S.A que pudieran convertir en inexacta a su declaración, más no se ha demostrado que por alguna de las vías que se forma el concepto de renta en la ley tributaria, la entidad haya dejado de tributar o las haya ocultado. Se trastorna el sentido de lo reclamado por la administración cuando en su afán desmedido de aplicar el artículo 92, apartado segundo del Código Tributario, enarbola la última parte del análisis del numeral tercero de la sindicada sentencia, obviando su primera parte y en esencia lo que ha denominado la jurisprudencia ánimo deliberado de ocultar la renta: "Elementos como la cuantía, el origen, la oportunidad de la percepción, pueden ser indicios de la existencia del ánimo deliberado de perjudicar al fisco y por ende no pueden ser considerados como ocultamiento.

Por el contrario cuando la cuantía del ingreso no declarado es significativa con relación al total del mismo o no pueda justificarse razonablemente el motivo de la omisión, el juzgador podría concluir que se trata de ocultamiento que en todo caso ha de ser deliberado para que se siga como consecuencia que la caducidad de la facultad verificadora se extienda en la magnitud señalada en el inciso segundo del artículo 94 del Código Tributario”. Esto acontece en el presente caso y mucho menos, se ajusta a las prescripciones del artículo 94.2, pues intenta de forma extemporánea la administración enmendar la declaración debidamente efectuada por el contribuyente, con base en temas de estricta contabilidad, para evitar que claudique su facultad determinadora como ocurrió en el asunto bajo examen.

\section{Conclusiones}

Que en el asunto de liquidación de pagos por diferencias sobre el impuesto a la renta correspondiente al ejercicio fiscal del 2012 de la Compañía RTT S.A se ha aplicado indebidamente por la administración tributaria el término de caducidad establecido en el artículo 94.2 del Código Tributario, con la finalidad de evitar que por su inacción claudique dicha prerrogativa legal.

Que es procedente advertir que ha caducado la facultad determinadora de la administración en esta oportunidad, pues a la situación fáctica narrada en la referida acta de liquidación de pagos por diferencias, le es aplicable el artículo 94.1 del Código Tributario, que hace fenecer la facultad determinadora de la administración tributaria a los tres años, desde la fecha de la declaración, que se corresponde con la declaración del impuesto a la renta del 
ejercicio económico 2012, pues lo narrado tanto en la comunicación de diferencias No. DZ8GSOOCDE16-00000219-M dictada el 24 de octubre de 2016 y notificada el 7 de noviembre de 2016, e igualmente en la contestación al reclamo administrativo efectuado en su contra por la multimencionada compañía, se base en irregularidades contables que inciden directamente en la declaración y no en el ocultamiento de rentas, y siendo de ese tenor, se ajusta al criterio jurisprudencial de que un acta es incompleta cuando se ocultan rubros y no por omisiones o inexactitudes contables de ellos, como en el caso que ocupa se manifiesta, y en ese sentido se reafirma la tesis de que ha caducado la facultad determinadora de la administración, conforme lo prevé el artículo 94, apartado primero.

Que no se ajusta el material fáctico de las actas que originan la controversia, emitidas por el Servicio de Rentas Internas, a los presupuestos legales que la sustentan, ni a los criterios jurisprudenciales rectores en la materia, vertidos tanto en triple reiteración como en fallos sucesivos e independientes de la Corte Nacional de Justicia, por los motivos narrados en el cuerpo de este trabajo y que huelgan se reiteren nuevamente en esta fase conclusiva del dictamen.

\section{Bibliografía}

Albaladejo, m. (2005). La simulación. Madrid: edisofer.

Alessandri, a. S. (2005). Tratado de derecho civil, partes preliminar y general, primera edición. Santiago de chile: editorial jurídica de chile.

Arias, d. B. (2008). Historia del sistema tributario ecuatoriano (1920-1999). Fiscalidad,

Arrioja, a., derecho fiscal, (2012), México; Themis.

Artana, d. (1987). Incentivos fiscales a la inversión industrial. Económica, 33.

Boletín mensual del banco central de ecuador. (1964). Oferta y utilización final de bienes y servicios. Ecuador.

Carrera, j. A., freire-serén, m. J., \& manzano, b. (2004). Rentabilidad social de la inversión pública española en infraestructuras. In xi encuentro de economía pública: [los retos de la descentralización fiscal ante la globalización]

Castro, 1. A. (2013). Análisis de la reforma tributaria en ecuador (2002-2012). Santiago de chile: CEPAL, naciones unidas.

Chapoy, b., derecho fiscal, (1996), México; UNAM.

Código civil. (2005). Quito: lexis s.a.

Código tributario. (2005). Quito: lexis s.a. 
Constitución de la república de ecuador. (2008). Quito: lexis s.a.

Diez Picazo, 1. Y.-3. (2014). Instituciones de derecho civil, volumen 1. Madrid: tecnos.

Garcés Moreano, r. C. (1978). Caducidad y prescripción. Revista de la universidad católica, no.20, año vi, 25-26.

García, c. (1996). Derecho tributario, tomo 1. Buenos aires: de palma.

Jarach. (1969). Curso superior de derecho tributario, tomo i. Buenos aires: edición nueva, liceo profesional cima.

Jaramillo, m. (2009). La caducidad en los actos de determinación de la obligación tributaria de la administración y su tratamiento en la legislación ecuatoriana. Revista de derecho no.11, p.129.

Lapatza, f. (1994). Derecho financiero español, 16 ed. Madrid: marcial Pons ediciones jurídicas s.a.

Ley de compañías. (1999). Quito: lexis s.a.

Ley del régimen tributario interno. (2010). Quito: lexis s.a.

Moreano, g. (1980). La caducidad en el sistema tributario ecuatoriano. Quito: puce.

Queralt. (2008). Derecho tributario. Navarra: Thomson Aranzadi.

Reglamento a la ley del régimen tributario interno. (2004). Quito: lexis s.a.

Valdés, r., curso de derecho tributario, (1996), santa fe de Bogotá; Themis

Witker, j., derecho tributario aduanero, (1999), México; UNAM 